\title{
Círculos Restaurativos na Socioeducação: A Visão dos Adolescentes e dos Participantes
}

\author{
Restorative Circles in Socioeducation: The Adolescents' and \\ Participants' Perspective
}

\author{
Lisiane Ligia Mella ${ }^{\mathrm{a}}$, Jéssica Limberger ${ }^{\mathrm{b}}, \&$ Silvana Terezinha Baumkarten ${ }^{\mathrm{c}}$ \\ ${ }^{a}$ Universidade de Passo Fundo(UPF), Passo Fundo, Brasil \\ ${ }^{b}$ Universidade do Vale do Rio dos Sinos (UNISINOS), São Leopoldo, Brasil \\ ${ }^{c}$ Universidade de Passo Fundo (UPF), Passo Fundo, Brasil
}

\begin{abstract}
Resumo: A atenção aos adolescentes brasileiros em conflito com a lei requer avanços na concretização dos direitos previstos na legislação. Entre esses direitos, está a realização de círculos restaurativos, que necessitam ser considerados. Para tanto, objetiva-se analisar os círculos restaurativos a partir da visão dos envolvidos sobre a participação do adolescente em conflito com a lei. Trata-se de uma pesquisa descritiva, de caráter qualitativo. Onze envolvidos nos círculos restaurativos participaram da pesquisa, respondendo a uma entrevista semiestruturada, entre eles dois adolescentes. Os dados foram analisados e dispostos em três categorias estabelecidas a posteriori: percepção dos adolescentes sobre o círculo restaurativo; percepção dos envolvidos no círculo restaurativo sobre a participação do adolescente; e mudança de visão dos participantes sobre o adolescente em conflito com a lei. Constatou-se que os adolescentes percebem o círculo restaurativo como uma possibilidade de responsabilização e de buscar o perdão da vítima, diante de seu arrependimento. Os participantes veem de maneira positiva a realização do círculo, principalmente desfazendo preconceitos para com o adolescente. Entretanto, alguns participantes demonstram incertezas quanto ao futuro do adolescente. Sugere-se um acompanhamento posterior ao círculo restaurativo, a fim de que o adolescente tenha o apoio necessário na mudança de vida.
\end{abstract}

Palavras-chave: adolescente, socioeducação, justiça restaurativa.
Abstract: The attention to Brazilian adolescents in conflict with the law requires advances in the implementation of rights as prescribed by the legislation. Among these rights we have the employment of restorative circles, which need to be considered. Therefore, the objective of this study is to analyze the restorative circles from the perspective of those involved in the participation of adolescents in conflict with the law. Eleven subjects involved in restorative circles (among them two adolescents) participated in this descriptive and qualitative research by answering a semistructured interview. The data was analyzed and placed in three categories established ex post facto to the adolescents' perception on the restorative circle; the perception of the subjects involved in the restorative circles about the teenagers' participation; and the change of perception of the participants concerning adolescents in conflict with the law. It was found that adolescents perceive the restorative circle as a possibility of accountability and seek forgiveness from the victim, due to his or hers repentance. Participants perceive the realization of the circle positively, mainly dispelling prejudices towards the adolescents. However, some participants show doubts about the future of the adolescents. A follow-up after the restorative circle is suggested, so that adolescents have the necessary support in changing their way of life.

Keywords: adolescent, socioeducation, restorative justice.

Contato: L. L. Mella. Rua Bento Gonçalves, No 273, Sala 402, Bairro Centro. CEP: 99010-000. Passo Fundo, Rio Grande do Sul, Brasil. Correio eletrônico: lisiane.mella@yahoo.com.br

Como citar: Mella, L. L., Limberger, J., \& Baumkarten, S. T. (2015). Círculos restaurativos na socioeducação: a visão dos adolescentes e dos participantes. Revista de Psicología, 24(2), 1-19.

http://dx.doi.org/10.5354/0719-0581.2015.36241 


\section{Introdução}

A adolescência é compreendida como um período de transformação entre a dependência infantil e a autonomia adulta, havendo mudanças físicas, psíquicas, afetivas e sociais (Brito, 2011). Partindo-se da abordagem sistêmica e psicossocial, entende-se que essa transformação não é única e inerente ao indivíduo, mas é um processo que ocorre em determinado momento de vida no sistema sociofamiliar, levando em consideração todas as partes que compõem esse sistema (Colle, 2001).

Os adolescentes vivenciam muitas angústias e conflitos nessa fase peculiar do desenvolvimento. Eles vão em busca de respostas para seus questionamentos e, quando as respostas não são encontradas em seu ambiente, isso pode lhes causar sofrimento e a impossibilidade de se comunicar com seu sistema sociofamiliar a não ser por passagens ao ato (Baumkarten, 2006). Portanto, a passagem ao ato diz respeito à dificuldade em que o adolescente se encontra, impossibilitado de colocar em palavras seu sofrimento, reagindo por meio de reações violentas contra os outros, contra o ambiente e contra si próprio, e essas reações são sintomas (Gervais, 1994). Os sintomas aparecem quando se rompe ou há estagnação no desenvolvimento do ciclo vital de uma família ou grupo social, e o adolescente, por conseguinte, viola as leis a fim de denunciar um sofrimento coletivo, pedindo ajuda (Pereira \& Sudbrack, 2008).

No Brasil, o adolescente que comete um ato infracional recebe atendimento socioeducativo. A socioeducação atende o adolescente através de medidas restritivas e privativas de liberdade. Conforme dados do Plano Nacional de Atendimento Socioeducativo Secretaria de Direitos Humanos da Presidência da República, SDH/PR, 2013), a população de adolescentes brasileiros soma pouco mais de 20 milhões de pessoas. Desta, menos de um adolescente em cada mil cumpre medidas socioeducativas. Em 2011 havia 19,595 adolescentes cumprindo medida em regime fechado e 88,022 em meio aberto, sendo $79.53 \%$ do sexo masculino. Esses dados revelam que as violências, em suas mais diversas manifestações, só poderão ser trabalhadas e transformadas a partir de medidas capazes de romper com sua banalização e com seu ciclo perverso (SDH/PR, 2013).

Muitas transformações e conquistas na esfera da justiça já ocorreram, principalmente através da Constituição Federal de 1988 e do Estatuto da Criança e do Adolescente, assegurando direitos às crianças e aos adolescentes. Porém, percebe-se que ainda há a necessidade de uma mudança de paradigma, reconstruindo realidades perante a falência estrutural do modelo tradicional de sistema criminal, onde a Justiça paralisa-se com o excesso de litígios apregoados pela cultura da guerra e da violência (Brancher \& Silva, 2008). Para além da punição, precisa-se restaurar laços sociais, compensar danos e gerar compromissos futuros mais harmônicos (Brancher, Todeschini \& Machado, 2008).

Esta é a proposta da Justiça Restaurativa, prática que objetiva aproximar o ofensor da vítima em um círculo denominado restaurativo, juntamente com seus respectivos familiares e representantes da comunidade, constituindo uma forma diferente e complementar ao sistema retributivo de lidar com os delitos (Brancher et al., 2008). A Justiça Restaurativa trata a questão criminal sob a perspectiva de que atos delitivos acometem violações nas relações entre as pessoas, e que, por causar um mal à vítima, à comunidade e ao próprio autor do delito, todos esses 
protagonistas envolvem-se num processo de restauração de um trauma individual e social (Pinto, 2005).

A Justiça Retributiva e a Justiça Restaurativa não se anulam, mas se somam no propósito de reparar as consequências vividas após uma infração, consequências que contemplam dimensões simbólicas, psicológicas e materiais (Jaccoud, 2005). As práticas restaurativas, portanto, não são feitas para substituir o sistema de justiça tradicional, mas sim para complementar as instituições legais existentes e melhorar o resultado do processo de justiça (Oxhorn \& Slakmon, 2005).

A metodologia da Justiça Restaurativa ocorre por meio da fala e da escuta e tem por objetivo externar a experiência pessoal de cada indivíduo, sendo cada uma importante e significativa. É a partir da construção mútua do sentido do conflito que surgirá uma resposta justa (Toews \& Zehr, 2006). Contudo, as práticas e políticas reais da Justiça Restaurativa assumem diferentes formas tanto dentro de um país como em países diferentes.

A Espanha, seguindo tendências europeias, utiliza a Justiça Restaurativa em diferentes níveis sociais (micro, meso e macro) e tem avançado em ações diante da vitimização causada pelo terrorismo (Olalde, 2014). No Paquistão, os programas de Justiça Restaurativa são apontados como uma forma de contribuir na diminuição de ciclos de violência e vingança, através de comitês locais. Na África, os princípios da Justiça Restaurativa possuem raízes profundas, onde o senso de comunidade é mais importante que o individual, sendo tanto os conflitos como as conquistas compartilhados coletivamente (Mangena, 2015). A Justiça Restaurativa também tem sido apontada como uma maneira de contribuir na resti- tuição de terras às vítimas do conflito armado na Colômbia (Saffon, 2010). Estudos também apontam desafios na implementação da Justiça Restaurativa, pois a mudança de paradigma requer mudanças nas formas de ver o crime e a justiça (Zehr, 2012). No Sistema Juvenil de Justiça de Chicago, há dificuldades de realização das técnicas restaurativas de maneira regular, sendo necessário mais planejamento junto aos membros da comunidade e legisladores (Tsui, 2014).

As formas contemporâneas mais debatidas de Justiça Restaurativa são os programas de encontro vítima-ofensor, as conferências de grupos familiares e os círculos de Justiça Restaurativa (Zehr, 2012). O método utilizado no Brasil é o círculo restaurativo, uma variação dos métodos restaurativos (Aertsen, 2013). Esse método é desenvolvido em três etapas: o pré-círculo, onde o coordenador faz um contato inicial com os participantes, explicando o procedimento e verificando a disponibilidade e o interesse, sendo a participação voluntária; o círculo restaurativo, encontro entre o ofensor, a vítima, seus respectivos familiares e representantes da comunidade, onde a partir da fala buscam restaurar o dano causado, através de um acordo; e o pós-círculo, onde os participantes reúnem-se novamente para avaliar o encontro e verificar se o acordo foi cumprido (Brancher et al., 2008).

As contribuições da Justiça Restaurativa para o sistema de justiça tradicional vão desde o campo do Direito até os benefícios aos participantes do círculo restaurativo, pois a política criminal não deve se resumir a sanções cumpridas nos estabelecimentos penais (Macedo, 2013). Quando as necessidades dos envolvidos em um crime não são atendidas, há um déficit democrático, pois há falta de participação ativa no processo (Tiveron, 2013). Greene 
(2013) aponta que, no atual sistema de justiça, os ofensores retornam para suas comunidades sem indícios de mudanças ou inclusive ainda mais prejudicados, e que as comunidades sofrem e encontramse despreparadas para sua chegada. Assim, a Justiça Restaurativa surge a partir das carências do sistema punitivo atual, que se mostra ineficiente ao segregar a vítima, fracassar na responsabilização do autor e desconsiderar a comunidade (Pellenz \& De Bastiani, 2015; Greene, 2013).

Estudos têm apontado os benefícios psicológicos proporcionados aos participantes. Para a vítima, participar ativamente do processo contribui na resolução do conflito entre ela e o ofensor (Macedo, 2013). Além disso, a oportunidade da fala conferida à vítima colabora para que o processo seja elaborado e diminua a intensidade do trauma (Zehr, 2012). Nesse sentido, ela pode também reparar a sua dor de forma diferenciada, compreendendo as razões do ofensor e contribuindo para que ele possa encontrar um espaço melhor para a sua reintegração social (Ribeiro, 2013). Quanto ao ofensor, passar por este processo também permite que ele repare o dano ou o prejuízo causado e sempre que possível vá além de um reparo simples, oferecendo restituição e ajuda para os outros como para ele mesmo (Eglash em Mangena, 2015). Para os familiares, há também benefícios, pois colaboram na reconstituição de vínculos e na construção de algo valioso a partir de seus próprios recursos (Olalde, 2014). No que diz respeito à comunidade, Mangena (2015) afirma que os conflitos resolvidos com a sua participação tornam-se mais efetivos, por considerar que processos comunitários são mais importantes do que individuais e que os conflitos resolvidos coletivamente são também celebrados coletivamente.
No que diz respeito aos círculos restaurativos no contexto da socioeducação, estudos demonstram que a participação dos adolescentes em conflito com a lei em intervenções da Justiça Restaurativa pode reduzir o dano da exposição deles no sistema socioeducativo, ampliando a resolutividade dos planos de atendimento dessas medidas a partir de práticas restaurativas (Aguinsky et al., 2008). Assim, a partir de tais práticas, permite-se iluminar e revigorar o leque de experiências relacionadas à aplicação e ao cumprimento das medidas socioeducativas, com relação tanto aos operadores do sistema, como às partes do processo, incluindo a participação dos adolescentes em conflito com a lei, cuja expressão ao participar do processo é emblemática e altamente positiva (Brancher \& Arguinsky, 2006). Além disso, os índices de satisfação em estudo longitudinal revelam que noventa por cento dos adolescentes participantes manifestaram satisfação com a experiência, expressando terem sido tratados com respeito e justiça durante $\mathrm{o}$ procedimento restaurativo (Aguinsky et al., 2008).

No contexto brasileiro, a partir das mudanças previstas em lei, percebe-se já uma aproximação da Justiça Restaurativa com a socioeducação, por meio da Lei $12.594 / 2012$, que institui o SINASE (Decreto-lei $\mathrm{N}^{\mathrm{o}} 12.594,2012$ ). Em seu Artigo 35 , a referida lei expõe que a execução das medidas socioeducativas serão regidas por nove princípios, dentre eles o terceiro: "prioridade a práticas ou medidas que sejam restaurativas" (Decreto-lei $\mathrm{N}^{\mathrm{o}}$ 12.594, 2012). Além disso, o Programa de Execução de Medidas Socioeducativas de Internação e Semiliberdade do Rio Grande do Sul (PEMSEIS) também menciona a primazia para Procedimentos Restaurativos, com o objetivo de construir novas perspectivas de atendimento ao socioeducando, por meio da garantia do 
"exercício da cidadania e da corresponsabilização de todos os participantes envolvidos no Círculo Restaurativo" (SDH/PR, Governo do Rio Grande do Sul, Secretaria da Justiça e dos Direitos Humanos \& Fundação de Atendimento Socioeducativo do Rio Grande do Sul, 2014, p. 56).

Tendo em vista estudos que contemplam a Justiça Restaurativa como uma prática possível no campo da socioeducação (Aguinsky \& Capitão, 2008; Capitão \& Rosa, 2008; Konzen, 2007; Limberger, Mella, \& Baumkarten, 2013), percebe-se que há avanços significativos. No Brasil, destacam-se as práticas de Porto Alegre/RS e em Caxias do Sul/RS (Baquião, 2010; Brancher \& Silva, 2008). Para tanto, torna-se essencial analisar os círculos restaurativos depois da conclusão do processo, a fim de subsidiar futuras intervenções, tendo em vista a relevância da Justiça Restaurativa na contemporaneidade.

Diante dos fatos apresentados, propõe-se o problema de pesquisa: qual a percepção dos envolvidos sobre a participação do adolescente em conflito com a lei no círculo restaurativo? Desta forma, objetivase analisar os círculos restaurativos a partir da visão dos adolescentes e dos envolvidos sobre a participação do adolescente em conflito com a lei.

\section{Método}

Trata-se de uma pesquisa qualitativa, de alcance descritivo (Sampieri, Collado, \& Lucio, 2013). A pesquisa qualitativa busca compreender o significado de determinado fenômeno do ponto de vista dos participantes (Creswell, 2010), e o alcance descritivo permite especificar características e propriedades de fenômenos submetidos à análise (Sampieri et al., 2013).
Salienta-se que este estudo se configura como um recorte de um estudo maior, intitulado: Justiça Restaurativa na Socioeducação: repercussões nos participantes após o procedimento. Essa pesquisa foi aprovada pelo Comitê de Ética em Pesquisa da Universidade de Passo Fundo, sob parecer $\mathrm{N}^{\circ} 243.769$ e tinha como objetivo descrever as repercussões na vida dos participantes após a participação em círculos restaurativos no contexto da socioeducação. Os resultados evidenciaram que o perdão foi uma experiência transformadora durante o círculo restaurativo, sendo a motivação para o adolescente e a consequência para a vítima, perdoando a si mesma. Constatou-se que o diálogo proporcionou melhoras em todos os participantes e que a sociedade constrói a Justiça Restaurativa de maneira positiva, acreditando na proposta, visto que todos os participantes recomendariam o procedimento restaurativo.

\section{Participantes}

Os dados de contato dos participantes foram fornecidos pelo CASE, mediante apresentação do projeto de pesquisa. Desta forma, os treze participantes dos três círculos restaurativos foram contatados via telefone, compreendendo: os adolescentes em conflito com a lei e seus familiares, a vítima e seus familiares e os membros da comunidade. Contudo, dos treze envolvidos no procedimento restaurativo, dois recusaram-se a participar, totalizando onze participantes que aceitaram fazer parte do estudo, sendo: dois adolescentes em conflito com a lei; três familiares dos adolescentes; duas vítimas; dois familiares das vítimas; e dois representantes da comunidade. Tais participantes integraram três círculos restaurativos distintos, realizados entre agosto de 2011 e fevereiro de 2013. 


\section{Instrumentos}

Como instrumento, utilizou-se uma entrevista semiestruturada, composta por treze questões referentes ao círculo restaurativo. As questões abordam a motivação para participação, os sentimentos anteriores e posteriores à participação do círculo restaurativo, as percepções sobre o círculo restaurativo e sobre o adolescente em conflito com a lei e as dificuldades encontradas no processo. Além disso, havia questões sobre o conhecimento da Justiça Restaurativa para cada participante. A entrevista foi construída pelas autoras, a partir da revisão de literatura e das temáticas necessárias para responder aos objetivos da pesquisa. As perguntas foram realizadas com base em áreas amplas, formuladas intencionalmente a partir de embasamento científico sobre o tópico, conforme Flick (2004).

\section{Local de Coleta de Dados}

A coleta de dados foi realizada depois do término dos círculos restaurativos, no período de março a junho de 2013. As entrevistas foram realizadas individualmente, nas dependências de uma clínicaescola do curso de Psicologia de uma universidade do estado do Rio Grande do Sul, a fim de facilitar o acesso dos participantes e garantir um espaço onde pesquisador e participante não fossem interrompidos.

\section{Procedimento de Coleta de Dados}

No momento da entrevista, foram explicados os objetivos da pesquisa e foram feitas a leitura e a explicação do Termo de Consentimento Livre e Esclarecido (TCLE), assegurando o anonimato das informações e a voluntariedade no estudo. Os participantes concordaram em participar do estudo e assinaram o TCLE, ficando uma via com as pesquisadoras e outra via com os participantes. As entrevistas tiveram duração de aproximadamente 50 minutos, sendo gravadas mediante a autorização dos participantes. Todos os participantes responderam a todas as perguntas da entrevista.

\section{Procedimento de Análise de Dados}

Os dados foram analisados de forma qualitativa, a partir da técnica de análise do conteúdo temático (Creswell, 2010), que procura nas falas dos participantes os temas gerais recorrentes, proporcionando uma maneira de categorização dos dados, para que sejam compreendidos. Com a finalidade da reprodutibilidade (fiabilidade intercodificadores), os codificadores realizaram a codificação de maneira independente, sem haver consensos prévios. Em casos de discordância, um terceiro juiz recebeu as unidades de registro de forma pré-estruturada. A proporção de acordos entre codificadores foi de 0.80 . Os dados foram divididos em três categorias estabelecidas a posteriori: percepção dos adolescentes sobre o círculo restaurativo; percepção dos envolvidos no círculo restaurativo sobre a participação do adolescente; e mudança de visão dos participantes sobre o adolescente em conflito com a lei.

\section{Resultados}

Participaram da pesquisa onze sujeitos, sendo: dois adolescentes em conflito com a lei; três familiares dos adolescentes; duas vítimas; dois familiares das vítimas; e dois representantes da comunidade, com idades entre 14 e 52 anos. A caracterização dos participantes da pesquisa descreve-se conforme a Tabela 1, a seguir. 
Tabela 1

Caracterização dos Participantes da Pesquisa

\begin{tabular}{|c|c|c|c|c|c|}
\hline Sexo & Idade & Escolaridade & Profissão & Condição & $\begin{array}{c}\text { Conhecia a } \\
\text { Justiça } \\
\text { Restaurativa } \\
\text { antes do círculo? }\end{array}$ \\
\hline $\mathrm{M}$ & 14 & $\begin{array}{l}\text { Ensino fundamental } \\
\text { incompleto }\end{array}$ & Estudante & Adolescente & Não \\
\hline M & 17 & $\begin{array}{l}\text { Ensino fundamental } \\
\text { incompleto }\end{array}$ & Estudante & Adolescente & Não \\
\hline $\mathrm{F}$ & 27 & $\begin{array}{l}\text { Ensino superior } \\
\text { completo }\end{array}$ & $\begin{array}{l}\text { Auxiliar } \\
\text { administrativo }\end{array}$ & Vítima & Sim \\
\hline $\mathrm{F}$ & 52 & $\begin{array}{l}\text { Ensino superior } \\
\text { completo }\end{array}$ & Professora & Vítima & Sim \\
\hline $\mathrm{F}$ & 37 & $\begin{array}{l}\text { Ensino médio } \\
\text { completo }\end{array}$ & $\begin{array}{l}\text { Auxiliar de } \\
\text { cozinha }\end{array}$ & $\begin{array}{l}\text { Familiar do } \\
\text { adolescente }\end{array}$ & Não \\
\hline M & 38 & $\begin{array}{l}\text { Ensino fundamental } \\
\text { incompleto }\end{array}$ & $\begin{array}{l}\text { Auxiliar de } \\
\text { produção }\end{array}$ & $\begin{array}{l}\text { Familiar do } \\
\text { adolescente }\end{array}$ & Não \\
\hline $\mathrm{F}$ & 47 & $\begin{array}{l}\text { Ensino médio } \\
\text { completo }\end{array}$ & Do Lar & $\begin{array}{l}\text { Familiar do } \\
\text { adolescente }\end{array}$ & Não \\
\hline $\mathrm{F}$ & 21 & $\begin{array}{l}\text { Ensino superior } \\
\text { incompleto }\end{array}$ & Estudante & $\begin{array}{l}\text { Familiar da } \\
\text { vítima }\end{array}$ & Não \\
\hline M & 20 & $\begin{array}{l}\text { Ensino superior } \\
\text { incompleto }\end{array}$ & Estudante & $\begin{array}{l}\text { Familiar da } \\
\text { vítima }\end{array}$ & Não \\
\hline $\mathrm{F}$ & 23 & $\begin{array}{l}\text { Pós-graduação } \\
\text { incompleta }\end{array}$ & Psicóloga & $\begin{array}{l}\text { Representante } \\
\text { da comunidade }\end{array}$ & Sim \\
\hline M & 30 & $\begin{array}{l}\text { Curso } \\
\text { profissionalizante } \\
\text { completo }\end{array}$ & $\begin{array}{l}\text { Técnico de } \\
\text { enfermagem }\end{array}$ & $\begin{array}{l}\text { Representante } \\
\text { da comunidade }\end{array}$ & Não \\
\hline
\end{tabular}

Nota: Elaborado pelas pesquisadoras para fins desta pesquisa. A terminologia ofensor é utilizada na Justiça Restaurativa para se referir à pessoa que dirigiu uma ofensa a outra. Optamos por utilizar o termo adolescente em vez do termo ofensor, pois conforme Costa (2004, p. 79): "Não estamos diante de um infrator, que, por acaso, é um adolescente, mas, de um adolescente, que, por circunstâncias, cometeu ato infracional".

O adolescente de 17 anos, chamado de Antônio, também com a finalidade de preservar sua identidade, encontrava-se em cumprimento de medida socioeducativa de internação, por causa de um sequestro. Na ocasião, Antônio estava com mais dois jovens, sendo ele o único menor de idade e que dirigiu o carro utilizado no sequestro. Ao cumprir sua medida de internação, Antônio recebia atendimento psicológico e relatava à psicóloga seus pensamentos em relação à vítima e sobre seu desejo em falar com ela. A partir de então, iniciou-se o processo do círculo restaurativo. 


\section{Percepção dos Adolescentes Sobre o Cír- culo Restaurativo}

Roberto percebeu o círculo restaurativo como um espaço para conversar sem discutir, "um escutando o outro, sabendo a sua hora de falar", conforme sua fala. Para Antônio, o círculo possibilitou "pedir desculpa para a vítima e pensar". De fato, a motivação de ambos para participar do círculo foi pela oportunidade de buscar o perdão da vítima.
No que diz respeito às expectativas antes da realização do círculo, Roberto referiu a possibilidade de aproximar-se da vítima, sendo esta necessidade atendida. Entretanto, Antônio achava que a vítima iria "me encher de coisa", mas esperava que ela o desculpasse, fato que aconteceu no círculo. Os sentimentos vivenciados pelos adolescentes podem ser observados na Tabela 2.

\section{Tabela 2}

Sentimentos Antes, Durante e após o Procedimento Restaurativo

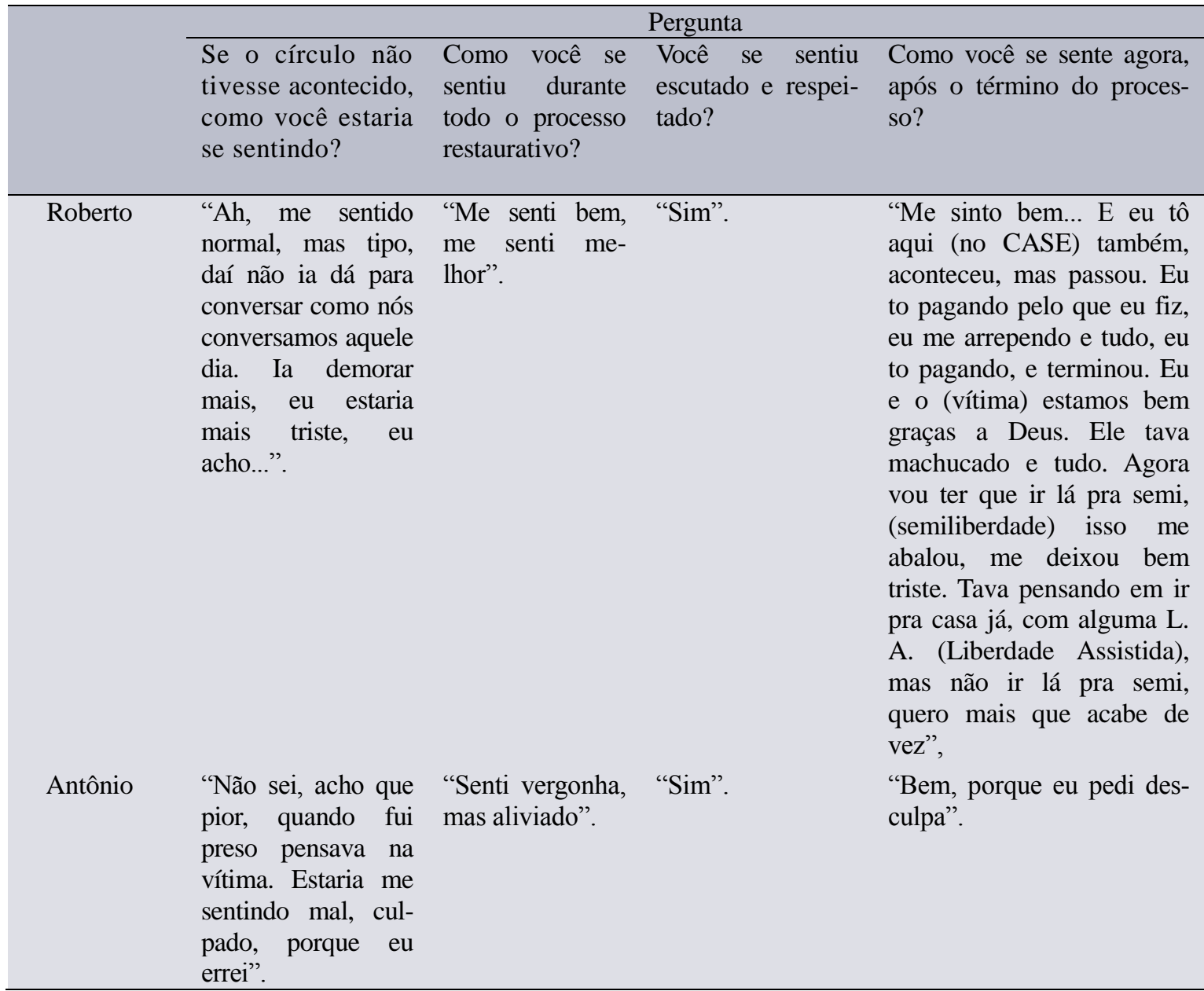

Nota: Elaborado pelas pesquisadoras para fins desta pesquisa.

Em relação à participação de Roberto e Antônio no círculo restaurativo, ambos acreditaram que sua presença foi importante para que o círculo ocorresse. Para
Roberto: "Eu pude falar, me expressar. Eu queria falar, conversar, eles me escutarem e eu escutei eles". Para Antônio: "Eu acho que foi importante por causa da vítima". 
No que diz respeito às dificuldades encontradas, Roberto relatou que não teve dificuldades no decorrer do círculo restaurativo. Já Antônio disse que achou difícil falar.

O círculo foi visto pelos adolescentes como uma possibilidade positiva de lidar com o que aconteceu. Conforme Roberto, foi um "um jeito mais... calmo... bom para resolver, sabe, mais civilizado". Além disso, ambos indicariam o círculo restaurativo a alguém que tenha passado por uma situação semelhante. Para Roberto: "indicaria porque foi uma coisa boa que reuniu de volta a família, para ajudar um ao outro. Eu recomendaria, porque é bem bom, foi bem bom pra mim". Conforme a visão sistêmica, o mundo é visto em termos de relações, como uma rede complexa de interconexões, onde as estruturas resultam da interdependência de suas partes (Anastácio \& Silva, 2012; Costa, 2010). Para tanto, cabe pensar o círculo restaurativo de forma sistêmica e interconectada por uma complexa rede de relações.

\section{Percepção dos Envolvidos no Círculo Restaurativo Sobre a Participação do Adolescente}

As vítimas mostraram-se ambivalentes sobre a participação do adolescente no círculo restaurativo, no sentido de ele se responsabilizar: "Olha, aparentemente contribuiu. Ele se mostrou arrependido, mas dava para ver que ele não tinha noção real do que estava acontecendo". Para outra vítima: "Eu espero que tenha contribuído, tô acreditando que sim. No círculo tive a impressão que ele refletiu bastante, tanto que a família já mudou de bairro, pra sair das companhias, então a família o ajudou também”.
Outros aspectos levantados pelas vítimas dizem respeito à importância de saber o que estava acontecendo com o adolescente e de fazer questionamentos. Para uma vítima: "No círculo eu soube o que estava acontecendo com ele, de ver a mãe dele, me senti mais tranquila". Outra vítima diz:

Eu pude fazer muitos questionamentos no círculo. Eu disse: "Tá, tu queria matar?". Ele disse: "Não!". Aí eu disse: Mas eu poderia ter te matado!". Aí ele olhou... Eu disse: "Sim, você apontou a arma para o vidro e não para mim!". Então tu vê toda a inexperiência. Mas tem também todo o lado da responsabilidade, como ele tinha uma arma?

Sobre esses questionamentos, Zehr (2008) afirma que embora as perdas materiais sejam importantes às vítimas, pesquisas feitas entre vítimas de crimes mostram que elas em geral dão prioridades a outras necessidades, sendo uma delas a sede de respostas e de informações.

Quanto aos familiares do adolescente, eles percebem como positiva a participação do jovem. Para a mãe de Antônio, o círculo ajudou, pois:

Ali foi bem conversado, bem explicado, ninguém se desentendeu. Todo mundo conversou, deu conselho, até a vítima perguntou para ele se faltava alguma coisa, ele disse que não. Aí ela disse: "Então por que fazer isso? Por que ir atrás de crime?". Acho que ele botou na cabeça, né.

Tal visão também se assemelha com a do padrasto de Roberto: "Foi bastante importante, para ele se responsabilizar pelos atos dele. Até hoje ele tá indo bem, ajudou bastante o círculo, acho que se não 
tivesse o círculo seria difícil de conversar". Entretanto, a mãe de Roberto possui dúvidas em relação a contribuição do círculo restaurativo:

Não serviu para nada, porque eu acho que o Roberto continua o mesmo. Eu tenho medo, sinto que ali vou ter muita dor de cabeça, que o que ele falou não foi de coração. Ele é mau caráter mesmo. Mas foi bom que o círculo aconteceu, porque eles (Roberto e a vítima) se entenderam.

A dificuldade de o adolescente expressarse no círculo restaurativo foi apontada pela mãe de Antônio:

Ah, lá eu me senti assim porque ele não falava, ele deveria ter falado mais, se aberto mais, mas é o jeito dele, ele e o pai dele, que a primeira vez nem falou, aí levei o irmão dele e piorou ainda... daí só eu falei. Eu acho que ele deveria ter falado mais com ela, ter falado mais. Acho que só isso.

Chama a atenção a expectativa da mãe de Antônio em relação à vítima:

Se ela (vítima) colocasse a boca nele eu não ia aceitar, ele é meu filho, por mais que ele errou, mas eu na minha frente não ia aceitar que ela colocasse a boca nele. Mas foi pelo contrário, eu tinha medo de encontrar ela bem violenta, mas é bem gente boa.

Os familiares das vítimas percebem que a participação do adolescente no círculo restaurativo foi uma importante oportunidade. Um familiar refere: "Acho que para ele ajudou alguma coisa. Ele merecia essa chance". A efetividade do círculo restaurativo no longo prazo é apontada pelo irmão de uma vítima:
Eu espero que tenha sido válido e que isso não se repita ou que algo pior não aconteça para qualquer pessoa. Mas eu acho que tem que esperar pra ver. $\mathrm{Eu}$ também tenho esperança que tenha sido positivo, mas eu acho difícil mudar, por isso que é importante esse acompanhamento pós-círculo, mais em longo prazo.

Para a filha de uma vítima houve dificuldades na comunicação:

O adolescente, ele nem olhava pra gente, eu não sei se ele realmente tava ali, mas a mãe dele demonstrava bastante preocupação, que ela tava interessada em conhecer a gente, saber realmente como a mãe tava. Porque a mãe dele eu acho que realmente tava mais envolvida do que ele. Ele até fez uma cartinha pra minha mãe, então isso até a gente notou que com ela ele tinha dado mais atenção.

Percebe-se a participação dos familiares como uma potencialidade do processo, visto que processos restaurativos exigem que os membros da família do autor do delito e da vítima se reúnam para resolver o conflito, aceitando a responsabilidade (Mangena, 2015).

Os representantes da comunidade veem o círculo restaurativo como uma possibilidade de o adolescente responsabilizar-se por seus atos. Um representante afirma: "Com certeza o círculo levou ele a pensar mais sobre o que aconteceu". Outro representante da comunidade diz:

Com certeza ele se responsabilizou e pôde saber o que a vítima estava sentindo no momento do ato, o temor dela, se ela ia ver as filhas dela novamente. Acho que isso me sensibilizou muito. Justamente isso ele me 
comentou, que realmente não imaginava as proporções. Ao parar para analisar, ver a pessoa falando frente a frente, a família dele, a mãe dele. Eu coloquei o quanto a gente gostava dele.

Para a representante da comunidade, a participação do adolescente foi significativa. Conforme sua fala: "eu acho que é um momento muito importante para o adolescente, ali que vai mostrar quem realmente se preocupa com ele, aliás, que tem pessoas que realmente se preocupam com ele".

Após o cumprimento da medida socioeducativa, um representante da comunidade compreende que o círculo restaurativo possibilita ao adolescente:

poder hoje andar pelas ruas, sem ter medo de ver a pessoa em que ele causou o transtorno. De seguir a vida dele em diante, de consciência limpa, que o que ele fez ele já pagou, ele já explicou as intenções dele para a vítima.

Além disso, acrescenta:

Eu acho importante para ele (adolescente) e para ela (vítima) ouvirem como eu via ele, enquanto a sociedade. Ela (vítima) teve uma oportunidade para ver que justamente foi por impulso. Não é uma coisa ruim, planejada, tanto é que depois de sair do CASE, agora ele trabalha, está casado, constituiu uma família.

O mesmo representante da comunidade ressalta: "Eu tô até emocionado de relembrar, de reviver isso que passou, me sinto bem por ter contribuído na restauração dele na sociedade, e espero que continue assim e que acredito muito nele. Me sinto muito bem por ter contribuído". A parti- cipação da comunidade revela-se fundamental nos círculos restaurativos, como destaca Tsui (2014), considerando que o objetivo dos círculos está em construir um senso de comunidade em torno dos valores partilhados pela comunidade.

\section{Mudança de Visão dos Participantes So- bre o Adolescente em Conflito com a lei}

Percebe-se que participar do círculo restaurativo contribuiu para que o irmão de uma vítima pudesse mudar sua visão a respeito do adolescente, conforme refere:

eu acho que muda o modo da gente ver algumas coisas que acontecem hoje. A gente vê na tevê que um jovem está causando um delito e a gente pensa: de repente não é tudo isso que a gente pensa, tu entende? O que será que tem por trás disso? $\mathrm{O}$ que levou ele a fazer isso? Acho que de primeira a gente pensa: tem que prender, tem que matar. Mas eu acho que se fosse pensado dessa forma antes do círculo de repente poderia ter acontecido uma tragédia.

Esta mudança também é perceptível em um representante da comunidade, que expõe que:

tem pessoas que só veem o lado ruim e não procuram ver o que levou a causa desse fato né, do sequestro e tal. Eu saí bem por ter contribuído para a vida social dele e justamente por ter contribuído para a justiça.

A filha de uma vítima diz:

participei para saber realmente o que tava sendo feito com ele e a gente pôde saber sobre a vida dele, como é que era, conhecer a família dele. Até ele não era um cara assim... acho que até ele tinha 
ainda jeito, sabe. Porque conhecendo ele eu não vi uma pessoa violenta, agressiva que eu imaginava conhecer.

Um familiar de uma vítima também demonstra essa mudança de visão de mundo:

A gente pensa: qual é a melhor solução? Tu vai prender o cara e daí? Ele vai sair e vai mudar? Ele tem chance de falar e ouvir o que aconteceu? Ele tem noção do que ele fez? Às vezes não. Mas acho que é isso, com a Justiça Restaurativa a pessoa tem a noção da realidade da outra pessoa e tenta entender e dissolver isso.

\section{Discussão}

Analisar uma intervenção implica compreender as percepções de todos os envolvidos, integrando os significados, a sua visão de mundo e as formas singulares que cada um atribui à sua participação no processo. Os dois adolescentes participantes do círculo restaurativo possuíam atos infracionais diferentes, advindos de contextos diferentes. Entretanto, ambos encontravam-se em uma etapa peculiar do desenvolvimento, a adolescência. Essa etapa é definida como um momento de transição da infância para a maturidade física, psíquica e social, em que o adolescente sai do sistema familiar para procurar no externo respostas a suas necessidades de identificação, afirmação, afiliação, autonomização e diferenciação. Quando tais respostas não são encontradas em seu ambiente, há um sofrimento e uma dificuldade na comunicação com sua família, com os adultos e seus educadores, resultando em passagens ao ato, com a prática de atos infracionais (Baumkarten, 2006).

Sendo assim, os atos infracionais ou qualquer outra expressão de sofrimento psíquico do adolescente podem ser compreendidos como meios e/ou recursos de expressão do sofrimento que este sujeito vivencia, sendo a transgressão das normas a forma encontrada pelo jovem de se comunicar com o outro, podendo ser representada tanto como uma denúncia de um sofrimento coletivo como um pedido de ajuda (Penso, Conceição, Costa, \& Carreteiro, 2012).

Os adolescentes deste estudo encontravam-se em cumprimento de medida socioeducativa de internação. Nessa etapa, a realização de círculos restaurativos possibilitou um espaço de escuta, de fala e de promoção da empatia, ressignificando o ato cometido. Conforme foi percebido nas falas dos adolescentes, a realização dos círculos restaurativos durante o cumprimento da medida foi muito importante, pois eles puderam expressar o que estavam sentindo, em um processo de diálogo e respeito, além de realizar uma ação concreta e simbólica para reparar o ato infracional. Tais dados corroboram o estudo realizado por Capitão (2008), no qual o adolescente participante do estudo sente-se importante ao referir que "elas viram (...) aquela pessoa que eu sou, que eu não sou aquela pessoa que eles, o juiz pensa, ou outras pessoas" (Capitão, 2008, p. 143).

Nessa perspectiva, o diálogo é compreendido como uma forma de fazer circular sentidos e significados. De um arranjo linear para uma disposição sistêmica, os participantes se mantêm em círculo, não havendo privilégios (Pranis, 2010). Nesse encontro, há um respeito construído pelos diretamente interessados, "o resultado sustenta-se porque faz viver" (Konzen, 2007, p. 93), em meio a uma virada paradigmática para a cultura do aprendizado.

A motivação que levou os adolescentes a participarem do círculo restaurativo foi a possibilidade de pedir desculpas pelo que fizeram. Assim, aliviaram a culpa, buscando o perdão. Para Groisman (2013, p. 131), 
o perdão é "uma atitude ou ato individual de uma pessoa em relação a outra que lhe infringiu uma lesão emocional ou física de maior ou menor intensidade". Para o mesmo autor, o perdão possui um caráter duplo, sendo ele interpessoal e intrapessoal; o primeiro está ligado ao plano objetivo relacional e o segundo ao plano subjetivo, ou seja, como aquele que sofreu a violência vai lidar com a situação.

Para os adolescentes, o perdão no plano subjetivo torna-se fundamental, pois auxilia na passagem de uma condição de ofensor para adolescente. Ao buscar o perdão, o adolescente assume o que fez, demonstrando arrependimento e responsabilidade, condições que, para Zehr (2008), favorecem o perdão pela vítima.

Se a vítima precisa de uma vivência de perdão, assim também o ofensor. De que outra forma poderia encontrar solução para sua culpa? De que outro modo seguir adiante e construir uma nova vida? Como desenvolver uma identidade saudável e um sentido de valor próprio, como se salvar a não ser pelo perdão? (Zehr, 2008, p. 48).

Ambos os adolescentes narraram que a sua participação foi importante no círculo restaurativo, porque puderam falar e se expressar. No processo restaurativo, a principal ferramenta é a fala que se apresenta no diálogo, carregada de emoções. Ao falar, os participantes possuem uma oportunidade única. Em que outro momento encontrariam-se e falariam sobre o que aconteceu? De que outra forma poderiam admitir o passado, confiar no presente e ter esperança no futuro? De fato, ao demonstrar arrependimento, o adolescente assume seus atos e as repercussões destes, sendo esta a condição necessária para a responsabilização e a mudança. Compreende-se que a culpa paralisa, impossibili- tando emergir a responsabilidade, que ocorre quando se está consciente das consequências das próprias ações, aceitandoas (Maturana \& Verden-Zoller, 2004). Assim, há uma transformação paradigmática que substitui uma cultura de culpa por uma cultura de aprendizado (Braithwaite, 2006).

Percebe-se que o círculo restaurativo também proporcionou que os adolescentes se sentissem bem ao participar, pois o encontro não buscava a punição, mas sim a responsabilização. Além disso, o adolescente não está sozinho, com ele encontram-se seus familiares e a comunidade, facilitando o apoio e o auxílio para o cumprimento do acordo restaurativo final (Tiveron, 2013). Sendo assim, acredita-se que tal prática cumpre sua função de contribuir na ressocialização do adolescente.

O alívio sentido após a realização do círculo proporcionou a sensação de "dever cumprido", simbolizando um rito de passagem em que o adolescente deixa de ser visto como infrator, possibilitando a sensação de "conclusão" ou "resolução". Sabese que a palavra "conclusão" pode sugerir que o acontecido pode ser esquecido e o livro pode ser fechado, mas isso é impossível, pois esta palavra quer sugerir a capacidade de levar a vida adiante (Zehr, 2012). Além disso, ser escutado pela vítima permite que esta entenda suas razões e que o adolescente possa encontrar um espaço melhor para a sua reintegração social ( $\mathrm{Ri}$ beiro, 2013). No estudo de Brancher e Aguinsky (2006), uma vítima participante de um círculo restaurativo revela, reforçando as potencialidades do círculo restaurativo, que

eu tive um conjunto de coisas que até me fez bem sabe! Já pensou alguém te dá um tapa e tu não sabe quem foi, vai embora e tu não vê, tu vai ficar com aquele negócio, de quem te fez 
alguma coisa; foi bom, foi ótimo (Brancher \& Aguinsky, 2006, p. 16).

Para que o círculo restaurativo seja efetivo, é importante a participação de todos os envolvidos, principalmente dos familiares do adolescente. Pelas falas dos participantes, percebeu-se que a participação dos familiares do adolescente contribuiu no fortalecimento de uma rede de apoio, essencial no processo socioeducativo. Na medida em que os pais assumem a responsabilidade junto com o adolescente, ele se sente amparado, pois a solução de conflitos vai além do campo jurídico, contemplando as questões familiares (Macedo, 2013). Assim, através da rede das relações interpessoais que o adolescente constrói seu universo relacional, vai se reconhecendo como cidadão e construindo sua autoimagem (Sluzki, 1997).

Por outro lado, percebe-se que a descrença da mãe de Roberto e das vítimas e seus respectivos familiares é prejudicial ao adolescente. Portanto, uma realidade que favorece a "descrença" do adolescente em si mesmo e a ausência de esperança de uma vida melhor bloqueia toda a possibilidade de ação coletiva, o que provoca o enfraquecimento das redes (Pereira \& Sudbrack, 2008; Pilatti, Brussino, \& Godoy, 2013). Quando os participantes revelam que têm dúvidas quanto ao futuro do adolescente, emergem preconceitos oriundos de suas próprias visões de mundo, ao ver o adolescente como um infrator sem a possibilidade de mudança. Compreendese que tais incertezas podem estar relacionadas com a dificuldade de expressão de Antônio durante o decorrer do círculo restaurativo. Tanto ele quanto sua mãe e um familiar de uma vítima relataram o fato de ele não ter falado muito, o que pode ter gerado nos participantes uma ideia de que Antônio não estivesse envolvido ou preocupado com o círculo restaurativo.

Os representantes da comunidade, por sua vez, afirmaram ter a certeza de que o círculo contribuiu para a mudança do adolescente, constituindo importante rede de apoio que possibilita a ele reescrever sua história. Acreditar na mudança do adolescente implica em mudar a forma de vê-lo. Desta forma, a mudança do paradigma do Código de Menores para o Estatuto da Criança e do Adolescente reforça que a vulnerabilidade deixa de ser considerada como estigma ou como exclusão, para que os adolescentes sejam vistos a partir de seus direitos, em uma lógica da promoção de saúde para com os adolescentes em conflito com a lei (Sarriera, 2009). Nesse sentido, há uma convergência entre o ECA e a Justiça Restaurativa, pois suas práticas são estratégias eficazes do empoderamento dos adolescentes, bem como suas famílias e comunidades na resolução de conflitos e na promoção de direitos (Gaglietti, Silva, Zambillo, \& Razera, 2009).

Percebe-se ser imprescindível compreender o contexto em que o adolescente está inserido, entendendo o que está por trás do ato infracional. Conforme Zehr (2012),

números episódios de violência podem ser, na realidade, uma reconstituição de traumas vivenciados anteriormente, aos quais não foi possível reagir de modo adequado no passado. A sociedade tende a reagir infringindo mais traumas na forma de penas privativas de liberdade. Embo- 
ra a realidade traumática não possa ser usada como desculpa para o crime, ela deve ser compreendida e tratada (Zehr, 2012, p. 43).

Assim, o círculo restaurativo possibilita olhar para o adolescente e os sistemas nos quais está inserido, considerando sua autonomia e a responsabilidade e de todos os envolvidos. Desse modo, entende-se que os adolescentes em conflito com a lei têm o direito de participação nos círculos restaurativos durante $\mathrm{o}$ cumprimento da medida socioeducativa, como já prevê o Programa de Execução de Medidas Socioeducativas de Internação e Semiliberdade no Rio Grande do Sul (SDH/PR et al., 2014).

Por fim, identifica-se a necessidade de que a Justiça Restaurativa seja mais difundida, pois somente três dos onze participantes relataram que a conheciam antes de participar do círculo restaurativo. Este dado leva a pensar que a Justiça Restaurativa precisa se aproximar da sociedade, dando visibilidade a esta nova forma de resolução de conflitos que produz benefícios não só para quem participa do processo, mas também para o sistema de justiça como um todo, pelo seu caráter democrático e pela valorização da comunicação e do diálogo entre os todos envolvidos (Tiveron, 2013).

\section{Considerações Finais}

Por meio da análise da intervenção, foi possível compreender que os adolescentes percebem o círculo restaurativo como uma maneira positiva de lidar com o ato infracional, sendo uma ferramenta importante no cumprimento da medida socioeducativa. Os demais participantes, em especial os representantes da comunidade, vislumbram o círculo como uma possibilidade de o adolescente mudar sua história.

Há necessidade de práticas que atentem para as necessidades do adolescente, a fim de que se expresse da melhor forma, falando e refletindo sobre o que aconteceu. Com isso, as garantias previstas em lei precisam ser colocadas em prática, a fim de que mais adolescentes tenham a oportunidade de participar dos círculos restaurativos. Acredita-se que a Justiça Restaurativa necessita ser aplicada tanto nas medidas privativas de liberdade como nas restritivas, incluindo unidades de semiliberdade e meio aberto.

Como limitações deste estudo, ressaltase que apenas dois adolescentes participaram, sendo importante que futuras pesquisas analisem em profundidade as repercussões do círculo restaurativo na vida do adolescente. Sugere-se que estudos longitudinais sejam realizados, analisando o acompanhamento dado aos adolescentes a longo prazo. Sendo assim, o círculo restaurativo constitui uma possibilidade de intervenção, mas que não pode ser aplicado isoladamente, pois um acompanhamento pós-círculo é fundamental. O apoio das diversas esferas, incluindo as equipes técnicas, redes de serviços e igualmente dos familiares do adolescente são imprescindíveis. Tão importante quanto a prática dos círculos restaurativos na socioeducação, a constância dos valores da Justiça Restaurativa ao olhar para o adolescente pode transformar realidades. 


\section{Referências}

Aertsen, I. (abril, 2013). Institucionalizando a Justiça Restaurativa: A experiência belga e seus efeitos no sistema de justiça criminal. In D. Achutti (Coordenador), III Conferência Internacional de Justiça Restaurativa. Organização dos Advogados do Brasil, Porto Alegre, RS.

Aguinsky, B. G., Hechler, A. D., Comiran, G., Giuliano, D. N., Davis, E. M., Silva, S. E., \& Battisti, T. S. (2008). A introdução das práticas de Justiça Restaurativa no sis tema de justiça e nas políticas da infância e juventude em Porto Alegre: Notas de um estudo longitudinal no monitoramento e avaliação do Projeto Justiça para o Século 21. In L. Brancher \& S. Silva (Eds.), Justiça para o século 21: Instituindo práticas restaurativas: Semeando justiça e pacificando violência (pp. 01-37). Porto Alegre: Nova Prova. Retrieved from http://www.justica21.org.br/arquivos/bib_270.pdf

Aguinsky, B. \& Capitão, L. (2008). Violência e socioeducação: Uma interpelação ética a partir de contribuições da Justiça Restaurativa. Revista Katálysis, 11(2), 257-264. http://dx.doi.org/10.1590/S1414-49802008000200011

Anastácio, S. M. G. \& Silva C. N. (2012). Uma visão sistêmica do processo criador. Tessituras \& Criação, 3, 52-63. Retrieved from

http://revistas.pucsp.br/index.php/tessituras/article/view/8753

Baquião, L. A. (2010). Reflexões sobre o facilitador de Justiça Restaurativa: O caso Porto Alegre (Dissertação de mestrado em psicologia social, Pontifícia Universidade Católica de São Paulo, PUC-SP, São Paulo, Brasil). Retrieved from

http://www.justica21.org.br/arquivos/bib_428.pdf

Baumkarten, S. (2006). O significado da drogadição na adolescência. Passo Fundo: Editora Universidade de Passo Fundo.

Braithwaite, J. (2006). Emancipação e esperança. In C. Slakmon, M. R. Machado, \& P. C. Bottini (Org.), Novas direções na governança da justiça e da segurança (pp. 389-409). Brasília, DF: Ministério da Justiça.

Brancher, L. \& Aguinsky, B. (2006). Juventude, crime \& justiça: Uma promessa impagável. In Instituto Latino Americano das Nações Unidas para Prevenção do Delito e Tratamento do Delinquente (ILANUD), Associação Brasileira de Magistrados e Promotores da Infância e da Juventude (ABMP), Secretaria Especial de Direitos Humanos da Presidência da República (SEDH) (Org.), Justiça, adolescente e ato infracional (pp. 469493). São Paulo: INALUD.

Brancher, L. \& Silva, S. (2008). Justiça para o século 21: Semeando justiça e pacificando violências - três anos da experiência da Justiça Restaurativa na capital gaúcha. Porto Alegre: Nova Prova.

Brancher, L., Todeschini T. T., \& Machado, C. (2008). Justiça para o século 21: Instituindo práticas restaurativas. Manual de práticas restaurativas. Porto Alegre: Ajuris.

Brito, I. (2011). Ansiedade e depressão na adolescência. Revista Portuguesa de Clínica Geral, 27, 208-214. Retrieved from http://www.scielo.oces.mctes.pt/pdf/rpcg/v27n2/v27n2a10.pdf 
Capitão, L. C. D. (2008). Socioeducação em xeque: Interfaces entre Justiça Restaurativa e democratização do atendimento a adolescentes privados de liberdade (Dissertação de Mestrado do Programa de Pós-Graduação em Serviço Social inédita). Pontifícia Universidade Católica do Rio Grande do Sul, Porto Alegre.

Capitão, L. C. D. \& Rosa, L. C. (2008). A trajetória da FASE em sua conexão com a Justiça Restaurativa. In L. Brancher \& S. Silva, Justiça para o século 21: Semeando justiça e pacificando violências - três anos da experiência da Justiça Restaurativa na capital gaúcha (pp. 01-07). Porto Alegre: Nova Prova. Retrieved from http://www.justica21.org.br/arquivos/bib_279.pdf

Colle, F. X. (2001). Toxicomanias, sistemas e famílias: Onde as drogas encontram as emoções. (Trad. M. J. Pereira). Lisboa: Climepsi editores.

Costa, A. C. G. (2004). As bases éticas da ação sócio-educativa: Referenciais normativos e princípios norteadores. Retrieved from http://is.gd/CvUQ2w

Costa, L. F. (2010). A perspectiva sistêmica para a clínica da família. Psicologia: Teoria e Pesquisa, 26, 95-104. Retrieved from http://www.scielo.br/pdf/ptp/v26nspe/a08v26ns.pdf

Creswell, J. W. (2010). Projeto de pesquisa: Métodos qualitativo, quantitativo e misto. Porto Alegre: Artmed.

Decreto-lei $N^{o}$ 12.594. Institui o Sistema Nacional de Atendimento Socioeducativo - SINASE. Diário oficial da União Seção 1, (2012).

Flick, U. (2004). Uma introdução à pesquisa qualitativa. Porto Alegre: Bookman.

Gaglietti, M., Silva, G. A., Zambillo, M., \& Razera, J. (2009). Violência na escola: Intervenções e o processo de vitimização. In C. M. B. Cenci, L. R. C. Maurina, \& M. F. Wagner (Eds.), Intervenções da psicologia: Transitando entre diferentes contextos ( $\mathrm{pp}$. 74-92). Passo Fundo: IMED Editora.

Gervais, Y. (1994). La prévention des toxicomanies chez lês adolescents. Paris: L’Harmattan.

Greene, D. (2013). Repeat performance: Is restorative justice another good reform gone bad? Contemporary Justice Review, 16(3), 359-390.

http://dx.doi.org/10.1080/10282580.2013.828912

Groisman, M. (2013). A arte de perdoar: Terapia breve sistêmica no casamento e na infidelidade. Rio de Janeiro: Núcleo Pesquisas.

Jaccoud, M. (2005). Princípios, tendências e procedimentos que cercam a Justiça restaurativa. In C. Slakmon, R. C. P De Vitto, \& R. S. G. Pinto (Eds.), Justiça Restaurativa: Coletânea de artigos (pp. 163-188). Brasília: Ministério da Justiça, Programa das Nações Unidas para o Desenvolvimento. 
Konzen, A. A. (2007). Justiça Restaurativa e ato infracional: Desvelando sentidos no itinerário da Alteridade. Porto Alegre: Livraria do Advogado Editora.

Limberger, J., Mella, L. L., \& Baumkarten. (2013). Justiça Restaurativa e socioeducação: Repercussões nos participantes após o procedimento. Anais do Seminário Internacional de Mediação de Conflitos e Justiça Restaurativa, Santa Cruz do Sul. Retrieved from http://online.unisc.br/acadnet/anais/index.php/mediacao_e_jr/article/view/10907/1436

Macedo, M. F. S. (2013). Justiça Restaurativa: A importância da participação da vítima na pacificação dos conflitos. Revista da Seção Judiciária do Rio de Janeiro, 20(36), 95109. Retrieved from http://www4.jfrj.jus.br/seer/index.php/revista_sjrj/article/view/404

Mangena, F. (2015). Restorative justice's deep roots in Africa. South African Journal of Philosophy, 34(1), 1-12.

http://dx.doi.org/10.1080/02580136.2014.940572

Maturana, H. \& Verden-Zoller, G. (2004). Amar e brincar: Fundamentos esquecidos do ser humano. São Paulo: Palas Athena.

Olalde, A. J. (2014). Restorative encounters in terrorist victimization in Spain: Theoretical reflections and practical insights from social work. Oñati Socio-Legal Series, 4(3), 404-426.

Oxhorn, P. \& Slakmom, C. (2005). Micro-justiça, desigualdade e cidadania democrática. A construção da sociedade civil através da Justiça Restaurativa no Brasil. In C. Slakmon, R. C. P. De Vitto, \& R. S. G. Pinto (Eds.), Justiça Restaurativa. Coletânea de artigos (pp. 189-212). Brasília: Ministério da Justiça, Programa das Nações Unidas para o Desenvolvimento.

Pellez, M. \& De Bastiani, A. C. B. (2015). Justiça Restaurativa e resolução dos conflitos familiares. Revista Direito e Liberdade, 17(1), 231-250. Retrieved from http://is.gd/mPCPk6

Penso, M. A., Conceição, M. I., Costa, L. F., \& Carreteiro, T. C. C. (2012). Jovens pedem socorro: $O$ adolescente que praticou ato infracional e o adolescente que cometeu ofensa sexual. Brasília: Liber Livro.

Pereira, S. E. F. N. \& Sudbrack, M. F. O. (2008). Drogadição e atos infracionais na voz do adolescente em conflito com a lei. Psicologia: Teoria e Pesquisa, 24(2), 151-159. Retrieved from http://www.scielo.br/pdf/ptp/v24n2/03.pdf

Pilatti, A., Brussino, S. A., \& Godoy, J. C. (2013). Factores que influyen en el consumo de alcohol de adolescentes argentinos: un path análisis prospectivo. Revista de Psicología, 22(1), 22-36.

http://dx.doi.org/10.5354/0719-0581.2013.27716

Pinto, R. S. G. (2005). Justiça Restaurativa é possível no Brasil? In C. Slakmon, R. C. P. De Vitto \& R. S. G. Pinto (Eds.), Justiça Restaurativa. Coletânea de artigos (pp. 1940). Brasília: Ministério da Justiça, Programa das Nações Unidas para o Desenvolvimento.

Pranis, K. (2010). Processos circulares. São Paulo: Palas Athena. 
Ribeiro, D. V. H. (2013). Judicialização e desjudicialização: Entre a deficiência do legislativo e a insuficiência do judiciário. Revista de Informação Legislativa, 50(199), pp. 25 33. Retrieved from http://www2.senado.leg.br/bdsf/bitstream/handle/id/502916/000991396.pdf?sequence=1

Saffon, M. P. (2010). The project of land restitution in Colombia: An illustration of the civilizing force of hypocrisy? Revista Estudios Socio-Jurídicos, 12(2), 109-194. Retrieved from http://is.gd/9b5Us6

Sampieri, R. H., Collado, C. F., \& Lucio, M. P. (2013). Metodologia de pesquisa. Porto Alegre: Artmed.

Sarriera, J. C. (2009). A intervenção social: Suas origens, aspectos éticos, conceituais e metodológicos. In C. M. B. Cenci, L. R. C. Maurina, \& M. F. Wagner (Eds.), Intervenções da psicologia: Transitando entre diferentes contextos (pp. 13-24). Passo Fundo: IMED Editora.

Secretaria de Direitos Humanos, Presidência da República. (2013). Plano Nacional de atendimento socioeducativo 2013-2022. Retrieved from http://www.ibam.org.br/media/arquivos/planonacional.pdf

Secretaria de Direitos Humanos, Presidência da República, Governo do Rio Grande do Sul, Secretaria da Justiça e dos Direitos Humanos, \& Fundação de Atendimento Socioeducativo do Rio Grande do Sul. (2014). PEMSEIS: Programa de Execução de Medidas Socioeducativas de Internação e Semiliberdade do Rio Grande do Sul. Porto Alegre: SDH, FASE. Retrieved from http://www.fase.rs.gov.br/wp/wp-content/uploads/2014/11/PEMSEIS_v111.pdf

Secretaria de Direitos Humanos, Presidência da República, SDH/PR. (2013). Plano nacional de atendimento socioeducativo: Diretrizes e eixos operativos para o SINASE. Brasília: Autor.

Sluzki, C. E. (1997). A rede social na prática sistêmica. São Paulo: Casa do Psicólogo.

Tiveron, R. (2013). A Justiça Restaurativa e a emergência participativa na dicção do direito: contribuições para a teoria e para a prática democrática. Revista de Informação Legislativa, 50(197), 175-187. Retrieved from www2.senado.leg.br/bdsf/handle/id/496979

Toews, B. \& Zehr, H. (2006). Maneiras de conhecer para uma visão restaurativa de mundo. In C. Slakmon, M. R. Machado, \& P. C. Bottini (Eds.), Novas direções na governança da justiça e da segurança (pp. 419-432). Brasília-DF: Ministério da Justiça.

Tsui, J. C. (2014). Breaking free of the prison paradigm: Integrating restorative justice techniques into Chicago's Juvenile Justice System. The Journal of Criminal Law \& Criminology, 104(3), 636-665. Retrieved from http://is.gd/C4YxOs

Zehr, H. (2008). Trocando as lentes: Um novo foco sobre o crime e a justiça. São Paulo: Palas Athena.

Zehr, H. (2012). Justiça Restaurativa: Da teoria à prática. São Paulo: Palas Athena.

Data de recebimento: 12 de março de 2015

Data de aceitação: 26 de maio de 2015 